\title{
Advances in Wastewater Treatment
}

Editor(s): Giorgio Mannina, George Ekama, Hallvard Ødegaard, Gustaf Olsson

Advances in Wastewater Treatment presents a compendium of the key topics surrounding wastewater treatment, assembled by looking at the future technologies, and provides future perspectives in wastewater treatment and modelling. It covers the fundamentals and innovative wastewater treatment processes (such as membrane bioreactors and granular process). Furthermore, it focuses attention on mathematical modelling aspects in the field of wastewater treatments by highlighting the key role of models in process design, operation and control.

Other topics include:

- Anaerobic digestion

- Biological nutrient removal

- Instrumentation, control and automation

- Computational fluid dynamics in wastewater

- IFAS systems

- New frontiers in wastewater treatment

- Greenhouse gas emissions from wastewater treatment

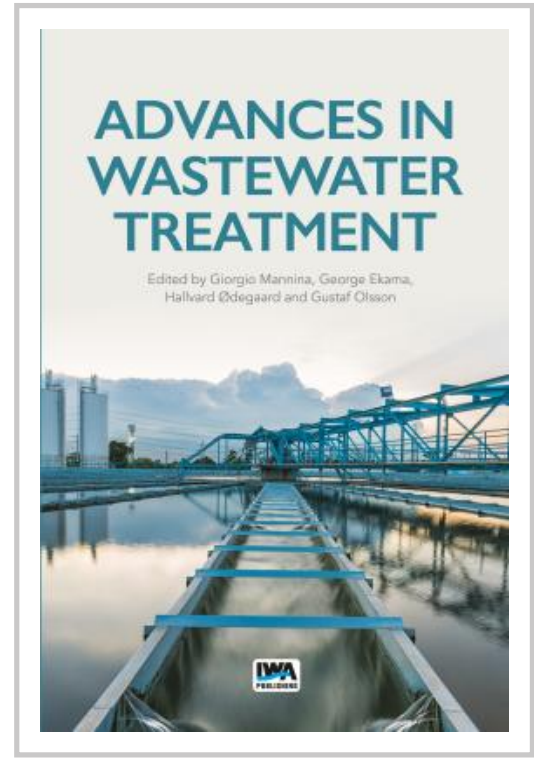

Each topic is addressed by discussing past, present and future trends. Advances in Wastewater Treatment is a valid support for researchers, practitioners and also students to have a frame of the frontiers in wastewater treatment and modelling.

Publication Date: 15/10/2018

ISBN13: 9781780409702

elSBN: 9781780409719

Pages: 400
Print:

Standard price: $£ 140$ / €175 / \$210

Member price: $£ 105 / € 131 / \$ 158$

eBook:

Standard price: $£ 140$ / €175 / \$210

Member price: $£ 105 / € 131 /$ \$158 